\title{
Transcriptional and Posttranscriptional Control of Cholesterol Homeostasis by Liver X Receptors
}

\author{
P. TONTONOZ \\ Howard Hughes Medical Institute and Department of Pathology and Laboratory Medicine, \\ University of California, Los Angeles, California 90095 \\ Correspondence: ptontonoz@mednet.ucla.edu
}

\begin{abstract}
The liver X receptors (LXRs) are nuclear receptors that play central roles in the transcriptional control of lipid metabolism. LXRs are activated in response to elevated cellular cholesterol levels, allowing them to function as "cholesterol sensors." Once activated, LXRs induce the expression of an array of genes involved in cholesterol absorption, efflux, transport, and excretion. They also inhibit cholesterol uptake by inducing the expression of Idol, an E3 ubiquitin ligase that catalyzes the ubiquitination and degradation of the low-density lipoprotein (LDL) receptor. Synthetic LXR agonists promote cholesterol efflux in vivo and inhibit the development of atherosclerosis in animal models. Conversely, loss of LXR expression in mice leads to pathologic lipid accumulation and accelerated atherosclerosis. The ability of LXRs to coordinate cellular and systemic sterol homeostasis makes them potentially attractive targets for intervention in human metabolic disease.
\end{abstract}

Cholesterol is an essential component of cellular membranes and a precursor for steroid hormone synthesis, and as such plays an important role in numerous biological systems. However, free cholesterol is toxic in excess and therefore its levels must be tightly controlled. Systemic cholesterol homeostasis reflects a balance between endogenous cholesterol synthesis, dietary uptake, reverse cholesterol transport, and biliary excretion. Excess plasma cholesterol in humans is a strong risk factor for cardiovascular disease (Lloyd-Jones et al. 2009). Statin drugs, which lower plasma cholesterol levels through inhibition of sterol synthesis, have had a positive impact on cardiovascular disease incidence and mortality (Pedersen et al. 2004). However, the prevalence of cardiovascular disease continues to increase. Many individuals are unable to reach their target lipid levels with statins alone. There is a need to identify novel targets that might permit further lowering of plasma cholesterol levels and disease risk.

The liver $\mathrm{X}$ receptor (LXR) and sterol regulatory element binding protein (SREBP) transcription factor families serve as the major transcriptional regulators of sterol metabolism in mammals (Repa and Mangelsdorf 2000; Tontonoz and Mangelsdorf 2003; Goldstein et al. 2006). Work over the past 15 years has painted a picture of these proteins working in a concerted and complementary fashion to maintain cellular and systemic cholesterol homeostasis. SREBPs are activated when cellular cholesterol levels fall. In response, SREBPs drive cholesterol synthesis and stimulate LDL receptor (LDLR) expression, leading to an increase in cellular cholesterol availability (Fig. 1). LXRs, on the other hand, are activated when cellular cholesterol levels rise. As outlined below, activated LXRs promote cholesterol efflux and simultaneously inhibit the uptake of cholesterol through the
LDLR pathway. The study of the LXR regulatory cascade is bringing fundamental insight into mechanisms of metabolic control and identifying new pathways that may potentially serve as targets for future cardiovascular therapies.

\section{LXRs: STEROL-RESPONSIVE NUCLEAR RECEPTORS}

Members of the nuclear receptor superfamily play important roles in development, reproduction, and metabolism (Evans 1988). These transcription factors have a highly conserved structure that includes an aminoterminal ligand-independent activation domain (AF-1), a zinc finger DNA binding domain (DBD), a carboxyterminal ligand-binding domain (LBD), and a liganddependent transcriptional activation function (AF-2). A major subset of nuclear receptors is the group of metabolite-activated receptors that form obligate heterodimers with the retinoid X receptor (RXR) (Mangelsdorf and Evans 1995). In the absence of their cognate ligands, most RXR heterodimers are bound to DNA in association with corepressors and maintain active repression of target genes (Glass and Rosenfeld 2000). Ligand binding triggers a conformational change in the receptor, the exchange of corepressors for coactivators, and the initiation of gene transcription. LXR $\alpha$ and LXR $\beta$ (NR1H3 and $\mathrm{NR} 1 \mathrm{H} 2$ ) are RXR heterodimeric receptors that function as important regulators of cellular and whole-body sterol homeostasis (Hong and Tontonoz 2008).

LXRs were originally cloned based on sequence homology with other nuclear receptors. Over the past 15 years, work from a number of laboratories has led to the recognition that LXRs are cholesterol sensors that play a central role in the coordination of sterol 
Low cellular cholesterol levels

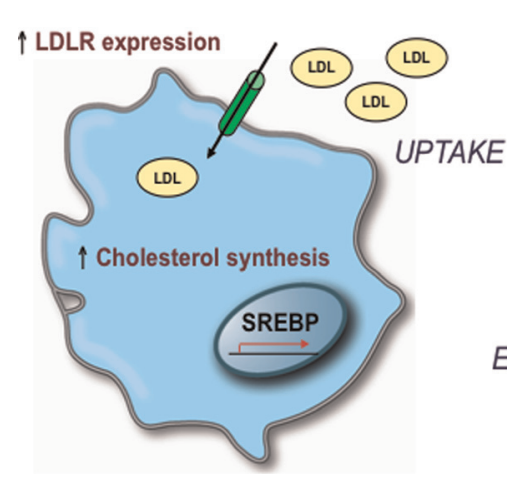

High cellular cholesterol levels

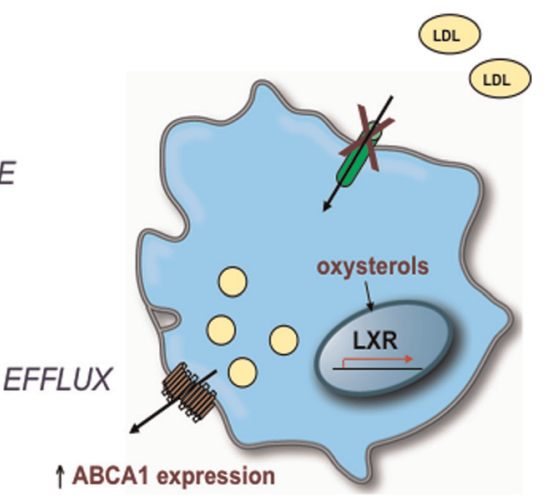

Figure 1. Reciprocal regulation of cholesterol metabolism by sterol regulatory element binding protein (SREBP) and liver X receptor (LXR) transcription factors. LDL, low-density lipoprotein; LDLR, LDL receptor.

metabolism. The natural ligands for LXRs are sterol metabolites such as 22(R)-hydroxycholesterol, 24(S)hydroxycholesterol, 27-hydroxycholesterol and 24(S), 25-epoxycholesterol (Janowski et al. 1996; Lehmann et al. 1997). LXR $\alpha$ and LXR $\beta$ share considerable sequence identity, respond to the same endogenous ligands, and regulate largely overlapping sets of target genes (Repa and Mangelsdorf 2002; Castrillo and Tontonoz 2004). However, the two LXRs exhibit different tissue distributions that likely reflect different biological roles. LXR $\beta$ is ubiquitously expressed, suggesting that it is a "housekeeping gene" important for the regulation of basal sterol homeostasis in all cells. LXR $\alpha$ expression is tissue-selective, being most prominent in liver, adipose tissue, adrenal glands, intestine, and myeloid cells. LXR $\alpha$ is postulated to be important for the prominent sterol metabolic demands of these particular cell types.

The LXRs form permissive heterodimers with the RXR, referring to the fact that the complex can be activated by ligand for either partner. LXR/RXR heterodimers bind to LXR-responsive elements (LXREs) consisting of direct repeats of the core sequence AGGTCA separated by four nucleotides (DR-4) (Willy and Mangelsdorf 1997). Ligand activation of LXRs also inhibits transcription from the promoters of certain genes such as inflammatory cytokines that do not contain LXREs. This phenomenon is referred to as transrepression (Glass and Rosenfeld 2000). The role of LXRs as modulators of inflammation and immunity has been the subject of several recent reviews (Ogawa et al. 2005; Zelcer and Tontonoz 2006; Bensinger and Tontonoz 2008).

\section{LXRS REGULATE SYSTEMIC CHOLESTEROL HOMEOSTASIS}

The identification of oxysterols as ligands of LXRs by Mangelsdorf and Kliewer provided the first clue to their function as transcriptional regulators of cholesterol metabolism (Janowski et al. 1996; Lehmann et al. 1997). Deletion of LXR $\alpha$ in mice was subsequently shown to lead to marked cholesteryl ester accumulation in liver when mice were challenged with a cholesterolrich diet (Peet et al. 1998). It is now recognized that this phenotype results from loss of the ability to regulate a series of genes involved in cholesterol removal from the body. In the liver where $\mathrm{LXR} \alpha$ is preferentially expressed, LXR $\alpha$ is required for optimal expression of Cyp7a1, a member of the cytochrome P450 family critical for bile acid synthesis, and the transporters ABCG5 and ABCG8 that are important for cholesterol secretion into bile (Peet et al. 1998; Repa et al. 2002; Yu et al. 2005).

LXR activation in mice was also found to inhibit cholesterol absorption from the diet, pointing to an important function for LXRs in the intestine as well. Hobbs and colleagues showed that the ability of LXR ligands to decrease intestinal sterol absorption is mediated by induction of ABCG5 and ABCG8 (Yu et al. 2005). These transporters form a functional heterodimer on the apical surface of the gut epithelium that limits cholesterol and plant-sterol absorption. Mutations in either ABCG5 or ABCG8 cause sitosterolemia, a rare genetic disease characterized by increased absorption of plant sterols and premature atherosclerosis (Lee et al. 2001a,b).

\section{LXRS ARE DOMINANT REGULATORS OF CELLULAR CHOLESTEROL EFFLUX}

In peripheral cells, LXRs are key regulators of the pathway of reverse cholesterol transport- the mechanism by which excess cholesterol from peripheral tissues is returned to the liver in the form of high-density lipoprotein (HDL) for subsequent excretion (Lewis and Rader 2005). Activation of LXRs in lipid-loaded cells such as macrophages leads to the induction of genes involved in cholesterol efflux in an attempt to reduce the intracellular cholesterol burden (Fig. 2). Treatment of mice with synthetic LXR agonists increases HDL levels and drives net cholesterol removal from the body (Repa et al. 2000b). Conversely, hypercholesterolemic mice lacking both LXR $\alpha$ and ApoE exhibit massive peripheral cholesterol 


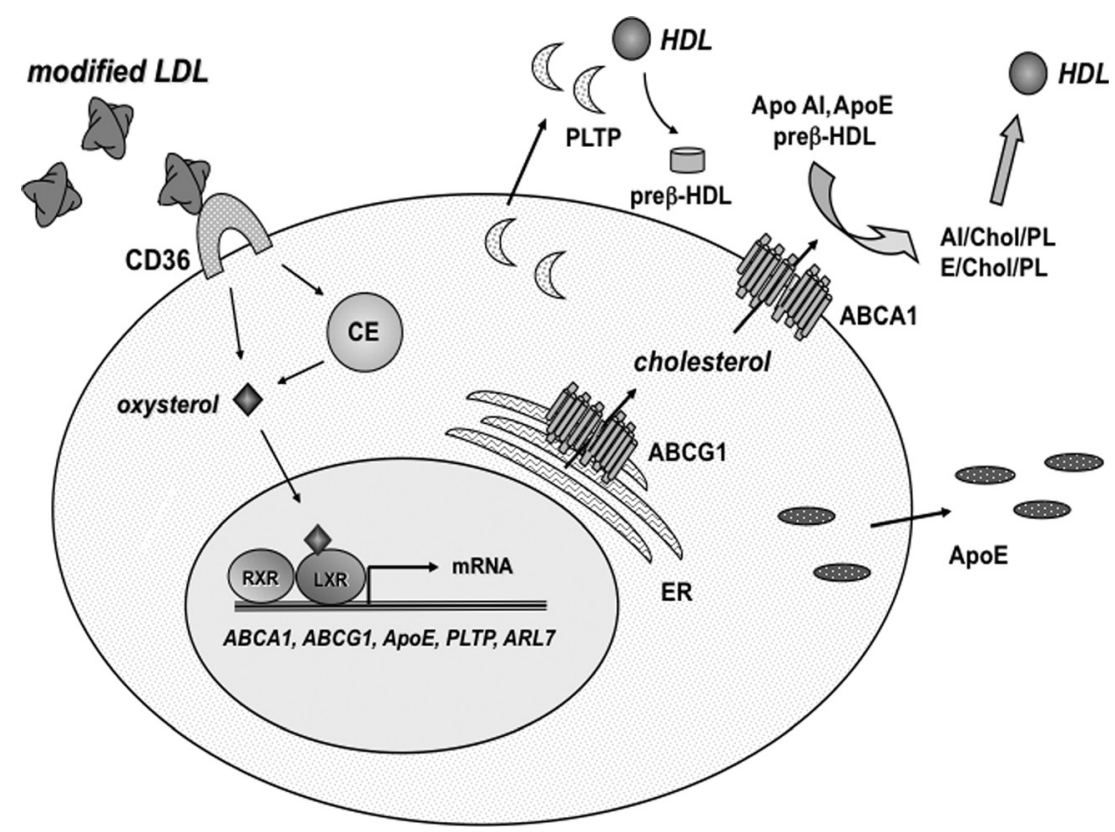

Figure 2. LXR coordinately regulates the cellular cholesterol efflux pathway. Modified LDL taken up by macrophages leads to the availability of oxysterol ligands for LXR. Activation of LXR in the nucleus induces the transcription of a cadre of genes involved in promoting cholesterol removal from the cell, including ABCA1, ABCG1, ApoE, PLTP, and ARL7. HDL, high-density lipoprotein.

deposition and atherosclerosis and as much as a fourfold elevation in total body cholesterol content (Bradley et al. 2007; Fig. 3).

A major mechanism whereby activated LXRs accomplish the removal of cholesterol from peripheral cells is through the transcriptional induction of the transporters ABCA1 (Costet et al. 2000; Repa et al. 2000b) and ABCG1 (Venkateswaran et al. 2000b; Kennedy et al. 2001; Sabol et al. 2005). These genes are direct targets for LXR/RXR heterodimers and their expression is strongly induced by natural LXR ligands or by loading of cells with lipoprotein-derived cholesterol. LXRs are in fact essential for lipid-inducible ABCA1 and ABCG1 expression, because induction is lost in cells lacking LXR $\alpha$ and LXR $\beta$ (Repa et al. 2000b; Venkateswaran et al. 2000b). Loss of ABCA1 function is the cause of Tangier disease, a rare disorder characterized by very low HDL and increased risk of cardiovascular disease (Bodzioch et al. 1999; Brooks-Wilson et al. 1999; Rust et al. 1999). LXR agonists are unable to stimulate cholesterol efflux in fibroblasts from Tangier patients, demonstrating that ABCA1 is essential for the LXRmediated efflux pathway (Venkateswaran et al. 2000a). Macrophage-specific loss of ABCA1 increases atherosclerotic lesion formation in mouse models (Aiello et al. 2002; van Eck et al. 2002). Numerous studies have implicated ABCA1 in the efflux of cholesterol and phospholipids to lipid-poor lipoproteins such as Apo-AI; it is likely that ABCA1 induction is a key contributor to the increased HDL levels seen following pharmacologic LXR activation (Schwartz et al. 2000; Venkateswaran et al. 2000a).

Induction of ABCG1 also contributes to LXRdependent cholesterol efflux and ABCG1 may act in

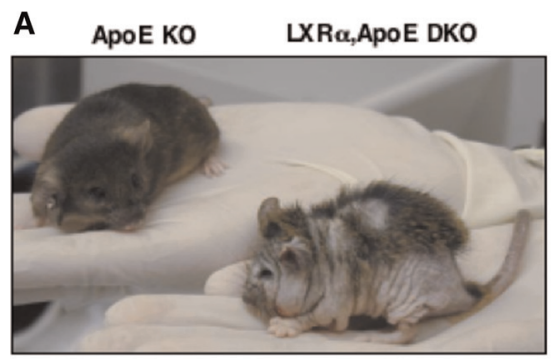

B

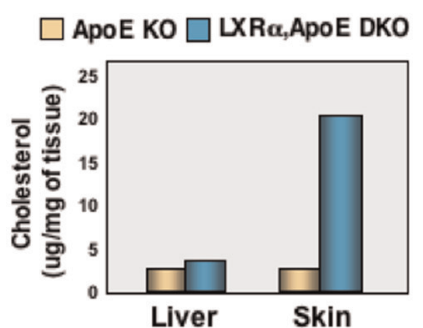

C

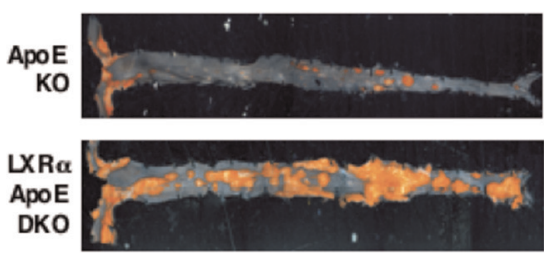

Figure 3. Cholesterol accumulation and advanced atherosclerosis in mice lacking both ApoE and LXR $\alpha$. $(A)$ Mice lacking both LXR $\alpha$ and ApoE develop alopecia and accumulate cholesterol in the skin. $(B)$ Quantification of cholesterol content in skin of ApoE and LXR $\alpha$,ApoE DKO mice. (C) Advanced atherosclerosis in LXR $\alpha$,ApoE DKO mice as assessed by Sudan IV staining of en face aortic preparations. 
concert with ABCA1. Mice lacking ABCG1 exhibit accumulation of lipid-laden macrophages in lung and liver when fed a high-cholesterol diet (Kennedy et al. 2005). In contrast to ABCA1, which effluxes cholesterol to ApoAI, ABCG1 has been demonstrated to facilitate cholesterol efflux to HDL (Klucken et al. 2000; Wang et al. 2004; Kennedy et al. 2005). At present, however, the cellular localization of ABCG1 is not well defined. Although there may be a small amount of ABCG1 on the plasma membrane, the bulk of ABCG1 protein in the cell is localized to intracellular membranes, and it is therefore unclear whether ABCG1 directly mediates efflux to HDL particles or facilitates this process by influencing intracellular cholesterol trafficking. In accordance with this latter idea, activation of LXRs in human macrophages has been reported to promote cholesterol trafficking to the plasma membrane at the expense of esterification (Rigamonti et al. 2005).

In addition to controlling the expression of efflux transporters, LXRs also promote cholesterol efflux by regulating the expression of a cadre of other factors involved in the reverse cholesterol transport pathway. LXRs induce the expression of a subset of apolipoproteins that serve as cholesterol acceptors, including ApoE, ApoCI, ApoCII, ApoCIV, and ApoD (Mak et al. 2002; Hummasti et al. 2004). LXRs also regulate the lipoprotein-remodeling enzyme PLTP, which may help to generate lipid-poor lipoprotein acceptors for cholesterol efflux (Laffitte et al. 2003), and promote the expression of ARL7, a protein postulated to be involved in trafficking of cholesterol to the plasma membrane for efflux (Hong et al. 2011).

\section{AN LXR-DEPENDENT PATHWAY FOR INHIBITION OF CHOLESTEROL UPTAKE}

The LDL receptor is a critical determinant of plasma cholesterol levels and the LDLR pathway has established links to human cardiovascular disease. Induction of LDLR mRNA in response to low intracellular cholesterol content is mediated primarily by the transcription factor SREBP-2 (Goldstein and Brown 1990). The precursor SREBP-2 protein resides in the ER and is transported to the Golgi under low sterol conditions where it undergoes proteolytic cleavage. Mature SREBP protein then translocates to the nucleus and promotes transcription of the LDLR gene, thereby facilitating the delivery of extracellular cholesterol to the cell (Goldstein et al. 2006). In recent years it has become clear that the LDLR pathway is also a target for posttranscriptional control. SREBPs induce the expression of proprotein convertase subtilisin/kexin type 9 (PCSK9), a protein involved in LDLR down-regulation (Lopez 2008; Steinberg and Witztum 2009). PCSK9 binds directly to the extracellular domain of the LDLR and alters its stability and trafficking, causing it to be degraded in lysosomes (Zhang et al. 2007; Cameron et al. 2008; Lopez 2008). Regulation of PCSK9 by SREBP has been proposed as a mechanism to prevent the re-uptake of newly secreted
VLDL particles by hepatocytes, facilitating their delivery to peripheral tissues (Grefhorst et al. 2008).

The coordinated regulation of intracellular sterol levels by the LXR and SREBP signaling pathways led us to hypothesize that LXR signaling might impact the uptake as well as the efflux of cholesterol. We found that treatment of a range of cell types including macrophages, fibroblasts, and hepatoma cells with the LXR agonist GW3965 markedly inhibited the binding and uptake of LDL. Unexpectedly, this effect was not due to an effect on LDLR mRNA. Rather, the ability of LXR agonists to inhibit LDL uptake was correlated with their ability to inhibit LDLR protein expression in an LXR-dependent manner (Zelcer et al. 2009) (Fig. 4).

Using a transcriptional profiling approach, we identified the mediator of the effect of LXR signaling on the LDLR. We proposed that this protein, which had been variably referred to as Mir and Mylip, be renamed Idol (for inducible degrader of the LDLR) in recognition of its biologic function. Idol contains a band 4.1 and Ezrin/Radixin/Moesin homology (FERM) domain that is known to mediate interactions with transmembrane proteins (Hamada et al. 2000; Pearson et al. 2000). In addition, Idol also contains a carboxy-terminal RING domain and had been proposed to act as an E3-ubiquitin ligase, although its biological substrate(s) had not been identified. Idol is a direct LXR target in both mice and humans. There is a binding site for LXR/RXR heterodimers in the $5^{\prime}$-flanking region of the Idol gene, and Idol mRNA expression is induced by LXR agonists in multiple cell types in vitro and in multiple tissues in vivo (Zelcer et al. 2009).

Gain of function experiments with Idol expression vectors supported the hypothesis that Idol induction underlies the ability of LXRs to regulate LDLR abundance. Indeed, transfection of Idol cDNA into cultured cells, or expression of Idol in mouse liver via an adenoviral vector, strongly promotes the degradation of LDLR protein. The presence of a RING domain in Idol suggested that Idol might function as an E3 ubiquitin ligase. In support of this idea, we found that an Idol construct carrying a point mutation $(\mathrm{C} 387 \mathrm{~A})$ in the catalytic RING domain, which would be predicted to inactivate the E3 ligase activity, has no effect on LDLR protein levels. Furthermore, ubiquitination of the LDLR is dramatically enhanced by expression of active but not mutant Idol. Mutational analysis allowed us to determine the residues

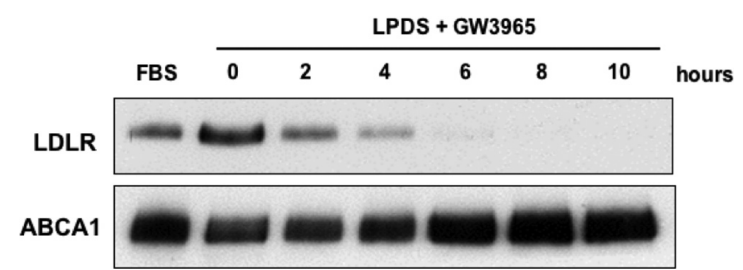

Figure 4. Activation of LXR reduced plasma membrane LDLR protein levels. Immunoblot analysis of LDLR and ABCA1 protein expression in mouse embryonic stem (ES) cells treated with $1 \mu \mathrm{M}$ of the LXR agonist GW3965 for the indicated times. FBS, fetal bovine serum; LDPS, lipoprotein-deficient FBS. 
within the LDLR cytoplasmic tail required for Idoldependent degradation. Mutagenesis revealed that either an intact K20 or an intact C29 was required for Idolmediated degradation. Combined mutation of the K20 and C29 residues not only blocks LDLR degradation by Idol, but also abolishes ubiquitination (Zelcer et al. 2009). The simplest model for Idol action on the LDLR is that Idol binds directly to the cytoplasmic tail of the LDLR. However, whether such a direct interaction occurs, or whether intermediate factors are involved in LDLR recognition, remains to be determined.

\section{REGULATION OF VLDLR, ApoER2 AND REELIN SIGNALING BY THE LXR-Idol PATHWAY}

In addition to the LDLR, it is now clear that two additional LDLR family members, VLDLR and ApoER2, are also targets for Idol-dependent degradation (Hong et al. 2010). Interestingly, both VLDLR and ApoER2 act as receptors for the signaling factor Reelin and have been implicated in neuronal development as well as lipid metabolism (Hiesberger et al. 1999; Beffert et al. 2005). We showed that LXR activation results in decreased Reelin binding to VLDLR and reduced Dab1 phosphorylation. The identification of VLDLR and ApoER2 as Idol targets suggests that this sterol-inducible E3 ubiquitin ligase may play as yet unrecognized roles in the central nervous system (CNS). Furthermore, the phosphorylation of Dab1 downstream of the VLDLR and ApoER2 has been reported to occur in tissues outside the CNS. Thus, the Idol pathway may also be involved in peripheral Dab1-dependent processes. The ability of Idol to regulate the Reeling pathway in vivo, however, remains to be addressed. Such functions would not be entirely surprising given recent work pointing to the importance of the LXR pathway in maintaining cholesterol homeostasis and attenuating inflammatory events in the CNS. LXR regulates ABCA1 expression and ApoE lipidation in the brain, and the LXR pathway is currently being explored as a potential target for therapeutic intervention in Alzheimer's and Nieman-Pick C disease (Koldamova et al. 2005; Zelcer et al. 2007; Jiang et al. 2008).

\section{LOSS OF Idol EXPRESSION IMPAIRS STEROL-DEPENDENT REGULATION OF THE LDLR PATHWAY}

To determine the function of Idol in cellular cholesterol metabolism, we generated Idol-deficient ES cells (Scotti et al. 2011). Analysis of these cells revealed that Idol is absolutely required for the effect of LXR on the LDLR pathway. Highly efficacious synthetic LXR agonists are unable to affect LDLR protein expression or LDL uptake in Idol null cells (Fig. 5). We also found that basal LDLR protein levels in Idol null cells are higher than in wildtype cells, despite the fact that Idol null cells express less LDLR mRNA. Importantly, these changes in LDLR protein levels translate into functional differences

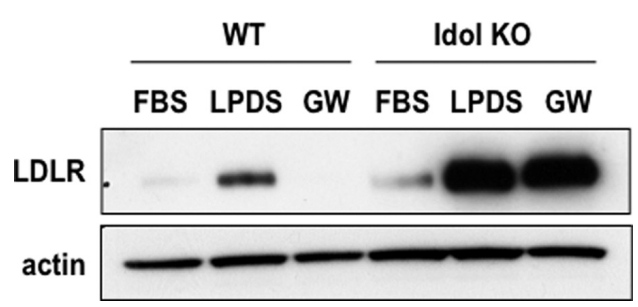

Figure 5. Altered LDLR regulation in cells lacking Idol expression. Wild-type (WT) or Idol null (KO) mouse ES cells were treated for $6 \mathrm{~h}$ with FBS, LDPS, or GW3965 (1 MM; $\mathrm{GW})$ as indicated. Protein expression was determined by immunoblotting.

in rates of cellular LDL uptake. Cells lacking Idol internalize LDL more readily than wild-type cells and are refractory to the inhibitory effects of LXR ligands on cholesterol uptake.

These studies also helped to clarify the complementary roles of the Idol and SREBP-2 pathways in feedback control of LDLR protein levels by sterols (Scotti et al. 2011). One advantage of the Idol pathway over the SREBP pathway may be the capacity for a rapid response to changing sterol levels. Oxysterol activation of LXR leads to a dramatic reduction in plasma membrane LDLR protein in as little as $2 \mathrm{~h}$. Although sterols still down-regulate LDLR expression in Idol null cells by suppressing LDLR gene transcription, the kinetics of this effect are much slower, supporting the hypothesis that Idol may be particularly important in the early response to sterols. Interestingly, specific oxysterols exhibit different temporal effects on LDLR expression, depending on their relative capacities to inhibit SREBP processing and activate LXRs.

Analysis of Idol null cells further provided insight into the functional relationship between the LXR-Idol and PCSK9 pathways. The two pathways are clearly complementary, as they both share the same protein substrates: LDLR, VLDLR and ApoER2 (Poirier et al. 2008; Shan et al. 2008; Zelcer et al. 2009; Hong et al. 2010). However, their mechanisms of action appear to be distinct. PCSK9 induces LDLR degradation primarily by binding the extracellular domain (Lopez 2008; Steinberg and Witztum 2009), whereas Idol works intracellularly. We initially suspected that Idol might act downstream of PCSK9-dependent LDLR internalization and might therefore be required for PCSK9-mediated degradation. However, PCSK9 is still able to stimulate LDLR degradation in Idol null cells, indicating that Idol and PCSK9 act in complementary but parallel pathways (Scotti et al. 2011). Furthermore, the effects of the statin drugs and Idol on LDLR protein levels are also additive and independent. Statins act by inhibiting cholesterol biosynthesis and triggering SREBP-dependent up-regulation of LDLR gene transcription (Miida et al. 2004; Liao and Laufs 2005). At least in cultured cells, loss of Idol expression stabilizes the increased LDLR protein levels induced by statins, thereby enhancing the pharmacological effect. 


\section{A UBIQUITIN LIGASE COMPLEX FOR LDLR DEGRADATION}

By analogy with other degradation pathways, the ubiquitination and subsequent degradation of the LDLR presumably depends on a cascade of ubiquitin transfer reactions carried out by E1, E2, and E3 enzymes. Although Idol had been identified as the E3, until recently, the identity of the E2 involved remained elusive. Because the LDLR is a membrane protein, it is challenging to study IDOL-LDLR interaction in a cell-free system. We hypothesized that Idol might employ the same E2 partner for both autoubiquitination and target LDLR ubiquitination and established an in vitro Idol autoubiquitination assay in order to identify Idol-interacting E2 enzymes. A screen of a panel of E2 enzymes led to the identification of the UBE2D family (UBE2D1-4) as E2 partners for Idol (Zhang et al. 2011). Importantly, we showed that UBE2Ds support not only auto-ubiquitination but also Idol-dependent ubiquitination of the LDLR in a cell-free system. In addition, we demonstrated that inhibition of UBE2D activity by overexpressing a dominant negative UBE2D enzyme inhibits the ability of Idol to degrade the LDLR in cells. Although the UBED2s were by far the most active in our screen, we cannot formally exclude the existence of additional E2 proteins capable of mediating Idol-dependent ubiquitination.

We solved the structure of Idol-RING domainUBE2D1 complex and demonstrated that disruption of UBE2D activity or the interaction interface between UBE2D1 and Idol inhibits the degradation of the LDLR (Zhang et al. 2011). Binding of UBED1 to Idol, similar to previously described E2-RING E3 interactions, is dependent on the E3 RING finger domain, which contains one histidine and seven cysteine residues that coordinate with two zinc ions (Joazeiro and Weissman 2000). RING domain E3 ligase share many structural similarities, as do different E2s in their E2 core domains. Consequently, the structural basis for the specific functional pairings between E2s and E3s has been a long-standing puzzle. Careful examination of the structure of the Idol-UBE2D1 complex and comparison of the sequences of the E2s that do and do not support Idol activity revealed residues at two key positions at the interface that appear to determine specificity, and their importance was confirmed with structure-guided mutations (Zhang et al. 2011). Thus, our analysis of the Idol ubiquitination complex fits well with prior studies suggesting that the specificity of E2:E3 pairings is determined by the complementarity of the intermolecular interfaces (Dominguez et al. 2004).

\section{THE LXR-Idol PATHWAY AND HUMAN METABOLISM}

The LXR-Idol pathway is conserved in human cells, but its role in human metabolism remains to be established. As outlined above, loss of Idol expression in cultured mouse cells increases LDLR protein levels;

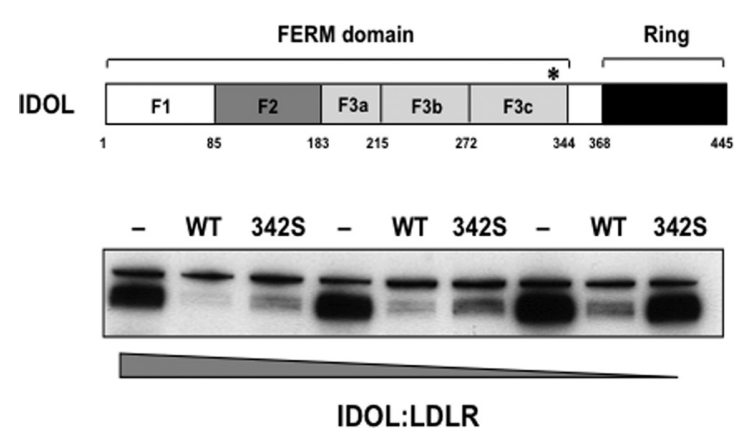

Figure 6. A functional polymorphism in the coding region of the human IDOL gene. (Top) Schematic representation of IDOL domain structure. Position of the N342S polymorphism is indicated by asterisk. (Bottom) Immuoblot analysis of LDLR protein levels following transfection of HEK293T cells with Idol N342 (wild type [WT]) or S342 expression vectors.

however, the effect of loss of Idol expression in humans is unknown. No null mutations in the human Idol gene have yet been described. Several genome-wide association studies have identified single nucleotide polymorphisms (SNPs) in the region of IDOL gene that are linked to LDL-C levels in human cohorts (Chasman et al. 2009; Teslovich et al. 2010). We recently identified a nonsynonymous SNP (N342S) in the coding region of the IDOL gene that alters the ability of Idol to degrade the LDLR (Weisglass-Volkov et al. 2011). Residue 342 maps to the Idol's FERM domain, a protein-protein interaction motif that is critical for Idol's ability to degrade the LDLR (Fig. 6). Our analysis suggests that this coding SNP may account for the various signals detected in the region of the Idol gene in previous genome-wide association studies. Furthermore, in a cohort of Mexican hyperlipidemic subjects, patients homozygous for the minor allele (N342; $\mathrm{MAF}=35 \%$ ) exhibited a $7 \%$ reduction in plasma cholesterol. These results provide in vivo evidence that modulation of Idol activity can affect human plasma LDL levels.

\section{CONCLUSIONS: THERAPEUTIC IMPLICATIONS OF THE LXR PATHWAY}

The ability of the LXR pathway to promote cholesterol efflux, inhibit cholesterol uptake and inhibit inflammation has spurred considerable interest in developing pharmacologic modulators of LXRs as human therapeutics. Although several diseases have been contemplated as possible targets for LXR ligands, most effort has focused on cardiovascular disease (Joseph and Tontonoz 2003). We showed in 2002 that systemic administration of a synthetic LXR agonist protects against the development of atherosclerosis in mice (Joseph et al. 2002). It was subsequently shown that pharmacologic LXR activation could even accomplish regression of established lesions in mice (Levin et al. 2005). Unfortunately, however, a major undesirable side effect also emerged. 
Activation of LXR in the liver raises plasma triglyceride levels, an independent risk factor for cardiovascular disease (Repa et al. 2000a). Current drug development strategies are therefore aimed at maximizing reverse cholesterol transport while limiting effects on hepatic lipogenesis.

One approach toward this goal would be to develop selective LXR $\beta$ agonists. Studies on mice lacking either LXR $\alpha$ or LXR $\beta$ have demonstrated that the lipogenic activity of LXR is predominately driven by $\mathrm{LXR} \alpha$, the main isotype expressed in the liver (Peet et al. 1998; Alberti et al. 2001). Thus, the development of an LXR $\beta$-selective compound might be a reasonable strategy to avoid hepatic side effects, as long as systemic LXR $\beta$ activation is sufficient to promote cholesterol efflux and inhibit atherosclerosis. Complementary studies of loss of LXR on atherosclerosis-susceptible backgrounds (ApoE null or LDLR null) have suggested that $\mathrm{LXR} \alpha$ plays a particularly important role in whole-body reverse cholesterol transport and atherosclerosis susceptibility (Bradley et al. 2007; Bischoff et al. 2010). Nevertheless, systemic administration of LXR ligand to mice lacking both $\mathrm{LXR} \alpha$ and ApoE still decreased peripheral cholesterol content and strongly reduced atherosclerosis, without increasing plasma triglyceride levels. These observations suggest that it is theoretically possible to uncouple hepatic lipogenesis from the peripheral reverse cholesterol transport program. The question now is whether suitable pharmacologic tools can be developed to accomplish this goal.

It is tempting to speculate that the LXR-Idol-LDLR pathway may also be a target for lipid modifying drugs. However, a number of outstanding biological questions need to be resolved. First is the relative contribution of PCSK9 and Idol pathways to tissue-specific posttranscriptional control of the LDLR in vivo. It is well established that PCSK9 acts primarily in the liver and that inhibition of PCSK9 has profound effects on plasma cholesterol levels in animal models and humans (Cohen et al. 2006; Horton et al. 2007). Idol is expressed at higher levels in peripheral cells such as macrophages compared with liver, suggesting that the primary biological role of Idol may be to protect the periphery from excess cholesterol uptake. At the same time, however, even small amounts of Idol can have substantial effects on LDLR protein levels, as is clear from the study of murine ES cells (Scotti et al. 2011). Furthermore, genome-wide association studies suggest that Idol activity can influence human plasma cholesterol levels, although the magnitude of this effect is not yet clear, because strong loss of function mutations have not been identified. Finally, preliminary studies point to possible species-specific differences in the LXR-Idol pathway in rodents versus humans. For example, LXR agonists degrade the LDLR more readily in human liver cells compared with rodent liver cells, and LXR agonists raise plasma LDL cholesterol levels in primates but not mice (Groot et al. 2005). Clearly, additional research is needed to explore whether pharmacologic modulation of Idol activity might have therapeutic utility.

\section{REFERENCES}

Aiello RJ, Brees D, Bourassa PA, Royer L, Lindsey S, Coskran T, Haghpassand M, Francone OL. 2002. Increased atherosclerosis in hyperlipidemic mice with inactivation of ABCA1 in macrophages. Arterioscler Thromb Vasc Biol 22: 630-637.

Alberti S, Schuster G, Parini P, Feltkamp D, Diczfalusy U, Rudling M, Angelin B, Bjorkhem I, Pettersson S, Gustafsson JA. 2001. Hepatic cholesterol metabolism and resistance to dietary cholesterol in LXR $\beta$-deficient mice. J Clin Invest 107: 565-573.

Beffert U, Weeber EJ, Durudas A, Qiu S, Masiulis I, Sweatt JD, Li WP, Adelmann G, Frotscher M, Hammer RE, et al. 2005. Modulation of synaptic plasticity and memory by Reelin involves differential splicing of the lipoprotein receptor Apoer2. Neuron 47: 567-579.

Bensinger SJ, Tontonoz P. 2008. Integration of metabolism and inflammation by lipid-activated nuclear receptors. Nature 454: $470-477$.

Bischoff ED, Daige CL, Petrowski M, Dedman H, Pattison J, Juliano J, Li AC, Schulman IG. 2010. Non-redundant roles for LXR $\alpha$ and LXR $\beta$ in atherosclerosis susceptibility in low density lipoprotein receptor knockout mice. J Lipid Res 51: 900-906.

Bodzioch M, Orso E, Klucken J, Langmann T, Bottcher A, Diederich W, Drobnik W, Barlage S, Buchler C, Porsch-Ozcurumez M, et al. 1999. The gene encoding ATP-binding cassette transporter 1 is mutated in Tangier disease. Nat Genet 22: 347-351.

Bradley MN, Hong C, Chen M, Joseph SB, Wilpitz DC, Wang X, Lusis AJ, Collins A, Hseuh WA, Collins JL, et al. 2007. Ligand activation of LXR $\beta$ reverses atherosclerosis and cellular cholesterol overload in mice lacking $\operatorname{LXR} \alpha$ and apoE. J Clin Invest 117: 2337-2346.

Brooks-Wilson A, Marcil M, Clee SM, Zhang LH, Roomp K, van Dam M, Yu L, Brewer C, Collins JA, Molhuizen HO, et al. 1999. Mutations in ABC1 in Tangier disease and familial high-density lipoprotein deficiency. Nat Genet 22: 336-345.

Cameron J, Holla OL, Berge KE, Kulseth MA, Ranheim T, Leren TP, Laerdahl JK. 2008. Investigations on the evolutionary conservation of PCSK9 reveal a functionally important protrusion. Febs J 275: 4121-4133.

Castrillo A, Tontonoz P. 2004. Nuclear receptors in macrophage biology: At the crossroads of lipid metabolism and inflammation. Annu Rev Cell Dev Biol 20: 455-480.

Chasman DI, Pare G, Mora S, Hopewell JC, Peloso G, Clarke R, Cupples LA, Hamsten A, Kathiresan S, Malarstig A, et al. 2009. Forty-three loci associated with plasma lipoprotein size, concentration, and cholesterol content in genome-wide analysis. PLoS Genet 5: e1000730.

Cohen JC, Boerwinkle E, Mosley TH Jr, Hobbs HH. 2006. Sequence variations in PCSK9, low LDL, and protection against coronary heart disease. New Engl J Med 354: $1264-1272$.

Costet P, Luo Y, Wang N, Tall AR. 2000. Sterol-dependent transactivation of the $\mathrm{ABC} 1$ promoter by the liver $\mathrm{X}$ receptor/retinoid X receptor. J Biol Chem 275: $28240-$ 28245.

Dominguez C, Bonvin AM, Winkler GS, van Schaik FM, Timmers HT, Boelens R. 2004. Structural model of the UbcH5B/CNOT4 complex revealed by combining NMR, mutagenesis, and docking approaches. Structure 12: 633-644.

Evans RM. 1988. The steroid and thyroid hormone receptor superfamily. Science 240: 889-895.

Glass CK, Rosenfeld MG. 2000. The coregulator exchange in transcriptional functions of nuclear receptors. Genes Dev 14: $121-141$.

Goldstein JL, Brown MS. 1990. Regulation of the mevalonate pathway. Nature 343: 425-430.

Goldstein JL, DeBose-Boyd RA, Brown MS. 2006. Protein sensors for membrane sterols. Cell 124: 35-46. 
Grefhorst A, McNutt MC, Lagace TA, Horton JD. 2008. Plasma PCSK9 preferentially reduces liver LDL receptors in mice. J Lipid Res 49: 1303-1311.

Groot PH, Pearce NJ, Yates JW, Stocker C, Sauermelch C, Doe CP, Willette RN, Olzinski A, Peters T, d'Epagnier D, et al. 2005. Synthetic LXR agonists increase LDL in CETP species. J Lipid Res 46: 2182-2191.

Hamada K, Shimizu T, Matsui T, Tsukita S, Hakoshima T. 2000. Structural basis of the membrane-targeting and unmasking mechanisms of the radixin FERM domain. EMBO J 19: 4449-4462.

Hiesberger T, Trommsdorff M, Howell BW, Goffinet A, Mumby MC, Cooper JA, Herz J. 1999. Direct binding of Reelin to VLDL receptor and ApoE receptor 2 induces tyrosine phosphorylation of disabled-1 and modulates tau phosphorylation. Neuron 24: 481-489.

Hong C, Tontonoz P. 2008. Coordination of inflammation and metabolism by PPAR and LXR nuclear receptors. Curr Opin Genet Dev 18: 461-467.

Hong C, Duit S, Jalonen P, Out R, Scheer L, Sorrentino V, Boyadjian R, Rodenburg KW, Foley E, Korhonen L, et al. 2010. The E3 ubiquitin ligase IDOL induces the degradation of the low density lipoprotein receptor family members VLDLR and ApoER2. J Biol Chem 285: 19720-19726.

Hong C, Walczak R, Dhamko H, Bradley MN, Marathe C, Boyadjian R, Salazar JV, Tontonoz P. 2011. Constitutive activation of LXR in macrophages regulates metabolic and inflammatory gene expression: Identification of ARL7 as a direct target. J Lipid Res 52: 531-539.

Horton JD, Cohen JC, Hobbs HH. 2007. Molecular biology of PCSK9: Its role in LDL metabolism. Trends Biochem Sci 32: $71-77$.

Hummasti S, Laffitte BA, Watson MA, Galardi C, Chao LC, Ramamurthy L, Moore JT, Tontonoz P. 2004. Liver X receptors are regulators of adipocyte gene expression but not differentiation: Identification of apoD as a direct target. J Lipid Res 45: $616-625$.

Janowski BA, Willy PJ, Devi TR, Falck JR, Mangelsdorf DJ. 1996. An oxysterol signalling pathway mediated by the nuclear receptor LXR $\alpha$. Nature 383: 728-731.

Jiang Q, Lee CY, Mandrekar S, Wilkinson B, Cramer P, Zelcer N, Mann K, Lamb B, Willson TM, Collins JL, et al. 2008. ApoE promotes the proteolytic degradation of A $\beta$. Neuron 58: $681-693$.

Joazeiro CA, Weissman AM. 2000. RING finger proteins: Mediators of ubiquitin ligase activity. Cell 102: 549-552.

Joseph SB, Tontonoz P. 2003. LXRs: New therapeutic targets in atherosclerosis? Curr Opin Pharmacol 3: 192-197.

Joseph SB, McKilligin E, Pei L, Watson MA, Collins AR, Laffitte BA, Chen M, Noh G, Goodman J, Hagger GN, et al. 2002. Synthetic LXR ligand inhibits the development of atherosclerosis in mice. Proc Natl Acad Sci 99: 7604-7609.

Kennedy MA, Venkateswaran A, Tarr PT, Xenarios I, Kudoh J, Shimizu N, Edwards PA. 2001. Characterization of the human ABCG1 gene: Liver X receptor activates an internal promoter that produces a novel transcript encoding an alternative form of the protein. J Biol Chem 276: 39438-39447.

Kennedy MA, Barrera GC, Nakamura K, Baldan A, Tarr P, Fishbein MC, Frank J, Francone OL, Edwards PA. 2005. ABCG1 has a critical role in mediating cholesterol efflux to HDL and preventing cellular lipid accumulation. Cell Metab 1: 121-131.

Klucken J, Buchler C, Orso E, Kaminski WE, Porsch-Ozcurumez M, Liebisch G, Kapinsky M, Diederich W, Drobnik W, Dean M, et al. 2000. ABCG1 (ABC8), the human homolog of the Drosophila white gene, is a regulator of macrophage cholesterol and phospholipid transport. Proc Natl Acad Sci 97: $817-822$.

Koldamova RP, Lefterov IM, Staufenbiel M, Wolfe D, Huang S, Glorioso JC, Walter M, Roth MG, Lazo JS. 2005. The liver X receptor ligand T0901317 decreases amyloid $\beta$ production in vitro and in a mouse model of Alzheimer's disease. J Biol Chem 280: 4079-4088.

Laffitte BA, Joseph SB, Chen M, Castrillo A, Repa J, Wilpitz D, Mangelsdorf D, Tontonoz P. 2003. The phospholipid transfer protein gene is a liver $\mathrm{X}$ receptor target expressed by macrophages in atherosclerotic lesions. Mol Cell Biol 23: 2182-2191.

Lee MH, Lu K, Hazard S, Yu H, Shulenin S, Hidaka H, Kojima H, Allikmets R, Sakuma N, Pegoraro R, et al. 2001a. Identification of a gene, $A B C G 5$, important in the regulation of dietary cholesterol absorption. Nat Genet 27: 79-83.

Lee MH, Lu K, Patel SB. 2001b. Genetic basis of sitosterolemia. Curr Opin Lipidol 12: 141-149.

Lehmann JM, Kliewer SA, Moore LB, Smith-Oliver TA, Oliver BB, Su JL, Sundseth SS, Winegar DA, Blanchard DE, Spencer TA, et al. 1997. Activation of the nuclear receptor LXR by oxysterols defines a new hormone response pathway. $J$ Biol Chem 272: 3137-3140.

Levin N, Bischoff ED, Daige CL, Thomas D, Vu CT, Heyman RA, Tangirala RK, Schulman IG. 2005. Macrophage liver X receptor is required for antiatherogenic activity of LXR agonists. Arterioscler Thromb Vasc Biol 25: 135-142.

Lewis GF, Rader DJ. 2005. New insights into the regulation of HDL metabolism and reverse cholesterol transport. Circul Res 96: $1221-1232$.

Liao JK, Laufs U. 2005. Pleiotropic effects of statins. Annu Rev Pharmacol Toxicol 45: 89-118.

Lloyd-Jones D, Adams R, Carnethon M, De Simone G, Ferguson TB, Flegal K, Ford E, Furie K, Go A, Greenlund K, et al. 2009. Heart disease and stroke statistics-2009 update: A report from the American Heart Association Statistics Committee and Stroke Statistics Subcommittee. Circulation 119: $480-486$.

Lopez D. 2008. PCSK9: An enigmatic protease. Biochim Biophys Acta 1781: 184-191.

Mak PA, Laffitte BA, Desrumaux C, Joseph SB, Curtiss LK, Mangelsdorf DJ, Tontonoz P, Edwards PA. 2002. Regulated expression of the apolipoprotein E/C-I/C-IV/C-II gene cluster in murine and human macrophages. A critical role for nuclear liver $X$ receptors $\alpha$ and $\beta$. J Biol Chem 277: 31900-31908.

Mangelsdorf DJ, Evans RM. 1995. The RXR heterodimers and orphan receptors. Cell 83: 841-850.

Miida T, Hirayama S, Nakamura Y. 2004. Cholesterolindependent effects of statins and new therapeutic targets: Ischemic stroke and dementia. J Atheroscler Thromb 11: $253-264$.

Ogawa S, Lozach J, Benner C, Pascual G, Tangirala RK, Westin S, Hoffmann A, Subramaniam S, David M, Rosenfeld MG, et al. 2005. Molecular determinants of crosstalk between nuclear receptors and toll-like receptors. Cell 122: 707-721.

Pearson MA, Reczek D, Bretscher A, Karplus PA. 2000. Structure of the ERM protein moesin reveals the FERM domain fold masked by an extended actin binding tail domain. Cell 101: $259-270$.

Pedersen TR, Kjekshus J, Berg K, Haghfelt T, Faergeman O, Faergeman G, Pyorala K, Miettinen T, Wilhelmsen L, Olsson $\mathrm{AG}$, et al. 2004. Randomised trial of cholesterol lowering in 4444 patients with coronary heart disease: The Scandinavian Simvastatin Survival Study (4S). 1994. Atherosclerosis Supplements 5: 81-87.

Peet DJ, Turley SD, Ma W, Janowski BA, Lobaccaro JM, Hammer RE, Mangelsdorf DJ. 1998. Cholesterol and bile acid metabolism are impaired in mice lacking the nuclear oxysterol receptor LXR $\alpha$. Cell 93: 693-704.

Poirier S, Mayer G, Benjannet S, Bergeron E, Marcinkiewicz J, Nassoury N, Mayer H, Nimpf J, Prat A, Seidah NG. 2008. The proprotein convertase PCSK9 induces the degradation of low density lipoprotein receptor (LDLR) and its closest family members VLDLR and ApoER2. J Biol Chem 283: 2363-2372. 
Repa JJ, Mangelsdorf DJ. 2000. The role of orphan nuclear receptors in the regulation of cholesterol homeostasis. Ann Rev Cell Dev Biol 16: 459-481.

Repa JJ, Mangelsdorf DJ. 2002. The liver X receptor gene team: Potential new players in atherosclerosis. Nat Med 8: $1243-1248$.

Repa JJ, Liang G, Ou J, Bashmakov Y, Lobaccaro JM, Shimomura I, Shan B, Brown MS, Goldstein JL, Mangelsdorf DJ 2000a. Regulation of mouse sterol regulatory elementbinding protein-1c gene (SREBP-1c) by oxysterol receptors, LXR $\alpha$ and LXR $\beta$. Genes Dev 14: 2819-2830.

Repa JJ, Turley SD, Lobaccaro JA, Medina J, Li L, Lustig K, Shan B, Heyman RA, Dietschy JM, Mangelsdorf DJ. 2000b. Regulation of absorption and ABC1-mediated efflux of cholesterol by RXR heterodimers. Science 289: 1524-1529.

Repa JJ, Berge KE, Pomajzl C, Richardson JA, Hobbs H, Mangelsdorf DJ. 2002. Regulation of ATP-binding cassette sterol transporters ABCG5 and ABCG8 by the liver X receptors $\alpha$ and $\beta$. J Biol Chem 277: 18793-18800.

Rigamonti E, Helin L, Lestavel S, Mutka AL, Lepore M, Fontaine C, Bouhlel MA, Bultel S, Fruchart JC, Ikonen E, et al. 2005. Liver X receptor activation controls intracellular cholesterol trafficking and esterification in human macrophages. Circul Res 97: 682-689.

Rust S, Rosier M, Funke H, Real J, Amoura Z, Piette JC, Deleuze JF, Brewer HB, Duverger N, Denefle P, et al. 1999. Tangier disease is caused by mutations in the gene encoding ATP-binding cassette transporter 1. Nat Genet 22: 352355.

Sabol SL, Brewer HB Jr, Santamarina-Fojo S. 2005. The human ABCG1 gene: Identification of LXR response elements that modulate expression in macrophages and liver. J Lipid Res 46: $2151-2167$

Schwartz K, Lawn RM, Wade DP. 2000. ABC1 gene expression and ApoA-I-mediated cholesterol efflux are regulated by LXR. Biochem Biophys Res Commun 274: 794-802.

Scotti E, Hong C, Yoshinaga Y, Tu Y, Hu Y, Zelcer N, Boyadjian R, de Jong PJ, Young SG, Fong LG, et al. 2011. Targeted disruption of the idol gene alters cellular regulation of the low-density lipoprotein receptor by sterols and liver $\mathrm{x}$ receptor agonists. Mol Cell Biol 31: 1885-1893.

Shan L, Pang L, Zhang R, Murgolo NJ, Lan H, Hedrick JA 2008. PCSK9 binds to multiple receptors and can be functionally inhibited by an EGF-A peptide. Biochem Biophys Res Commun 375: 69-73.

Steinberg D, Witztum JL. 2009. Inhibition of PCSK9: A powerful weapon for achieving ideal LDL cholesterol levels. Proc Natl Acad Sci 106: 9546-9547.

Teslovich TM, Musunuru K, Smith AV, Edmondson AC, Stylianou IM, Koseki M, Pirruccello JP, Ripatti S, Chasman DI, Willer CJ, et al. 2010. Biological, clinical and population relevance of 95 loci for blood lipids. Nature 466: $707-713$.
Tontonoz P, Mangelsdorf DJ. 2003. Liver X receptor signaling pathways in cardiovascular disease. Mol Endocrinol 17: 985-993.

van Eck M, Bos IS, Kaminski WE, Orso E, Rothe G, Twisk J, Bottcher A, Van Amersfoort ES, Christiansen-Weber TA, Fung-Leung WP, et al. 2002. Leukocyte ABCA1 controls susceptibility to atherosclerosis and macrophage recruitment into tissues. Proc Natl Acad Sci 99: 6298-6303.

Venkateswaran A, Laffitte BA, Joseph SB, Mak PA, Wilpitz DC, Edwards PA, Tontonoz P. 2000a. Control of cellular cholesterol efflux by the nuclear oxysterol receptor LXR $\alpha$. Proc Natl Acad Sci 97: 12097-12102.

Venkateswaran A, Repa JJ, Lobaccaro JM, Bronson A, Mangelsdorf DJ, Edwards PA. 2000b. Human white/murine ABC8 mRNA levels are highly induced in lipid-loaded macrophages. A transcriptional role for specific oxysterols. J Biol Chem 275: 14700-14707.

Wang N, Lan D, Chen W, Matsuura F, Tall AR. 2004. ATPbinding cassette transporters G1 and G4 mediate cellular cholesterol efflux to high-density lipoproteins. Proc Natl Acad Sci 101: 9774-9779.

Weisglass-Volkov D, Calkin C, Tusie-Luna T, Sinsheimer J, Zelcer N, Riba L, Tino A, Ordoñez-Sánchez ML, CruzBautista I, Aguilar-Salinas CA, et al. 2011. The N342S MYLIP polymorphism is associated with high total cholesterol and increased LDL receptor degradation in humans. J Clin Invest 121: $3062-3071$.

Willy PJ, Mangelsdorf DJ. 1997. Unique requirements for retinoid-dependent transcriptional activation by the orphan receptor LXR. Genes Dev 11: 289-298.

Yu L, Gupta S, Xu F, Liverman AD, Moschetta A, Mangelsdorf DJ, Repa JJ, Hobbs HH, Cohen JC. 2005. Expression of ABCG5 and ABCG8 is required for regulation of biliary cholesterol secretion. J Biol Chem 280: 8742-8747.

Zelcer N, Tontonoz P. 2006. Liver X receptors as integrators of metabolic and inflammatory signaling. $J$ Clin Invest 116: 607-614.

Zelcer N, Khanlou N, Clare R, Jiang Q, Reed-Geaghan EG, Landreth GE, Vinters HV, Tontonoz P. 2007. Attenuation of neuroinflammation and Alzheimer's disease pathology by liver X receptors. Proc Natl Acad Sci 104: 10601-10606.

Zelcer N, Hong C, Boyadjian R, Tontonoz P. 2009. LXR regulates cholesterol uptake through Idol-dependent ubiquitination of the LDL receptor. Science 325: 100-104.

Zhang DW, Lagace TA, Garuti R, Zhao Z, McDonald M, Horton JD, Cohen JC, Hobbs HH. 2007. Binding of proprotein convertase subtilisin/kexin type 9 to epidermal growth factor-like repeat A of low density lipoprotein receptor decreases receptor recycling and increases degradation. J Biol Chem 282: 18602-18612.

Zhang L, Fairall L, Goult BT, Calkin AC, Hong C, Millard CJ, Tontonoz P, Schwabe JW. 2011. The IDOL-UBE2D complex mediates sterol-dependent degradation of the LDL receptor. Genes Dev 25: 1262-1274. 


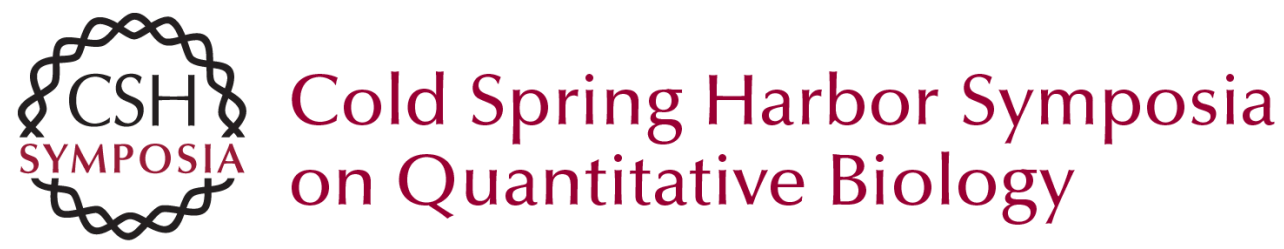

\section{Transcriptional and Posttranscriptional Control of Cholesterol Homeostasis by Liver X Receptors}

P. Tontonoz

Cold Spring Harb Symp Quant Biol 2011 76: 129-137 originally published online August 22, 2011 Access the most recent version at doi:10.1101/sqb.2011.76.010702

References This article cites 79 articles, 39 of which can be accessed free at: http://symposium.cshlp.org/content/76/129.full.html\#ref-list-1

License

Email Alerting Receive free email alerts when new articles cite this article - sign up in Service the box at the top right corner of the article or click here. 